\title{
Evaluation and Emergency Treatment of Criticlly III Neonate with Cyanosis and Respiratory Distress
}

\author{
Emina Hadzimuratovic ${ }^{1}$ and Admir Hadzimuratovic ${ }^{2}$ \\ 1Department of Neonatology, Pediatric Clinic, University Medical Center Sarajevo, \\ ${ }^{2}$ Department of Nephrology, Pediatric Clinic, University Medical Center Sarajevo \\ Bosnia and Herzegovina
}

\section{Introduction}

A severely ill neonate with cyanosis and respiratory distress is a diagnostic challenge. The clinician must perform a rapid evaluation to determine whether congenital heart disease is a cause so that potentially lifesaving measures can be instituted.

\section{Differential diagnosis}

The causes of cyanosis can be classified as respiratory, cardic, central nervous system ( CNS ) or other disorders.

\section{Evaluation}

During a physical examination if an infant appears blue, the following questions need immediate answer:

\subsection{Does the infant have respiratory distress?}

If the infant has increased respiratory effort with increased rate, retractions and nasal flaring, respiratory disease should be high on the list of differential diagnosis. Cyanotic heart disease usually presents without respiratory symptoms but can have effotless tachypnea ( rapid respiratory rate without retractions).

\subsection{Does the infant have murmor?}

A murmor usually implies heart disease. Transposition of great vessels can present without a murmor.

\subsection{Is the cyanosis continous, intermittent, sudden in oncet or occuring only with} feeding?

Intermittent cyanosis is more common with neurologic disorders, as these infants may have apneic spells alternating with periods of normal breathing. Continuous cyanosis is usually associated with intrinsic lung disease or heart disease. Cyanosis with feeding may occur 
with esophageal atresia and severe esophageal reflux. Cyanosis that disappears with crying may signify choanal atresia.

a. Respiratory diseases

1. Lung diseases
a. Hyaline membrane disease
b. Transiet tachypnea of the newborn
c. Pneumonia
d. Meconium aspiration

2. Air leak syndrome

3. Congenital defects ( eg. Diaphragmatic hernia, hypoplastic lungs, lobar emphysema, cystic adenomatoid malformation, diaphragmal abnormality )

\section{b. Cardiac diseases}

1. All cyanotic heart diseases includin transposition of great arteries, total anomalous pulmonary venous return, Ebstein's anomaly, tricuspid atresia, pulmonary atresia, pulmonary stenosis, tetralogy of Fallot, patent ductus arteriosus and ventricular septal defect

2. Persistent pulmonary hypertension

3. Severe congestive heart failure

\section{c. CNS diseases}

Periventricular-intraventricular hemorrhage, meningitis and primary seizure disorder can all cause cyanosis. Neuromuscular disorders such as WerdnongHoffmanndisease and congenital myotonic dystrophy can cause cyanosis.

\section{d. Other disorders}

1. Methemoglobinemia

2. Polycythemia/hyperviscostiy syndrome

3. Hypothermia

4. Hypoglycemia

5. Sepsis

6. Pseudocyanosis caused by fluorescent lighting

7. Respiratory depression secondary to maternal medications ( eg. magnesium sulfate and narcotics )

8. Shock

9. Upper airway obstruction. Choanal atresia is nasal passage obstruction caused most commonly by a bony abnormality. Other causes are laryngeal web, tracheal stenosis, goiter and Pierre Robin syndrome.

Table 1. Differential diagnosis of cyanosis in the newborn

\subsection{Is there differential cyanosis?}

If there is cyanosis of upper or lower part of the body only, this usually signifies serious heart disease. The more common pattern is cyanosis restricted to the lower part of the body, which is seen in patients with patent ductus arteriosus with left-to right shunt. Cyanosis restricted to the upper half of the body is seen occasionally in patients with pulmonary hypertension, patent ductus arteriosus, coarctation of aorta and D-transposition of great arteries. 


\subsection{What is the prenatal and delivery history?}

An infant of a diabetic mother has increased risk of hypoglycemia, polycytemia, respiratory distress syndrome and heart disease. Infection, which can occur with premature rupture of membranes, may cause shock and hypotension with resultant cyanosis. Amniotic fluiod abnormalities, such as oligohydramnios ( associated with hypoplastic lungs ) or polyhydramnios ( associated with esophageal atresia ), may suggest a cause for cyanosis. Cesarean section is associated with increased respiratory distress.

\section{Cardiac disease}

Congenital heart disease produces cyanosis when obstruction to right ventricular outflow causes intracardiac right-to-left shunting or when complex anatomic defects, unassociated with pulmonary stenosis, cause an admixture of pulmonary and systemic venous return in the heart. Cynosis from pulmonary edema may also develop in patients with heart failure caused by left-to-right shunts, although the degree is usually less severe. Cyanosis may be caused by persistence of fetal pathways, for example, right-to-left shunting across the foramen ovale and ductus arterious in the presence of persistent pulmonary hypertension of the newborn (PPHN).

\section{Cardiac evaluation of newborn infant}

In the cardiac evaluation of the newborn infant, understanding the circulatory status at birth is very important. As the result of fetal circulation, newborn infants have right ventricular (RV) dominance associated with a thick RV wall, elevated pulmonary vascular resistance (PVR), and a thick medial layer of the pulmonary arterioles. The thick pulmonary artery smooth muscle gradually becomes thinner, and it resembles that of the adult by the time the baby is age 6 to 8 weeks. Most perinatal changes in hemodynamics are related to the thinning of the pulmonary vascular smooth muscle, resulting in a gradual fall in the PVR and a loss of RV dominance of the neonate. Premature infants in general have lessRV dominance than full-term infants, and the PVR is not as high in the full-term neonate, which adds variability to the process. Because of these unique aspects of the perinatal circulatory system, the basic tools in the initial cardiac evaluation discussed are less reliable and the findings may be different in the newborn infant. Therefore echo studies are commonly performed in the neonatal cardiac evaluation. Some important aspects of normal and abnormal findings in physical examination, electrocardiograpgy (ECG), and chest x-ray films of the neonate are briefly reviewed in this chapter.

\subsection{Physical examination}

1. Normal physical findings that are unique in normal newborn infants

a. Heart rate is generally faster ( usually over 100 beats/min, with normal ranges from 70 to 180 beats/min) than that of older children and adults.

b. A varying degree of acrocyanosis is the rule rather than the exception.

c. Mild arterial desaturation with arterial $\mathrm{Po} 2$ as low as $60 \mathrm{mmHg}$ is not unusual in an otherwise normal neonate. This may be caused by an intrapulmonary shunt through an as yet unexpanded portion of the lungs or by a right-to-left arterial shunt through the patent foramen ovale (PFO). 
d. There is relative hyperactivity of the RV, with the point of maximal impuls (PMI)at the lower left sternal border (LLSB) rather than at the apex.

e. The second heart sound (S2) may be single in the first days of life, and occasionally an ejection click (reflecting pulmonary hypertension) is audible.

f. An innocent heart murmur may be present. The most common one in this age group is the pulmonary flow murmur of the newborn infant.

g. Peripheral pulses are easily palpable in all extremities, including the foot, in every normal infant.

2. Additional important features of premature infants

a. The pulmonary flow murmur of the newborn infant is more frequent and louder in premature than in full-term infants.

b. The likelihood of a patent ductus arteriosus (PDA) murmur is greater in premature infants.

c. The peripheral pulses normally appear bounding because of the lack of a normal amount of subcutaneous tissue.

3. Abnormal phycical findings

The following abnormal physical findings cardiac pathology.

a. Cyanosis, particularly when it does not improve with oxygen administration, requires further evaluation.

b. Decreased or absent peripheral pulses in the lower extremities suggest coarctation of aorta (COA). Generalized weak peripheral pulses suggest hypoplastic left heart syndrome (HLHS) or circulatory shock. Bounding peripheral pulses suggest an aortic run-off lesion such as PDA or persistent truncus arterious.

c. Tachypnea of greater than 60 breaths/min with or without retraction is abnormal.

d. Hepatomegaly may suggest a heart defect manifesting with congestive heart failure (CHF). A midline liver suggests asplenia or polysplenia syndrome.

e. A heart murmur may be a presenting sign of congenital heart disease (CHD). However, innocent murmurs are more common than pathologic murmurs.

f. An irregular rhythm or abnormal heart rate may suggest cardiac arrhythmias.

g. Blood pressure readings in the lower extremities 6 to $7 \mathrm{~mm} \mathrm{Hg}$ lower than those in the arm require further evaluation for COA.

\subsection{Blood gases}

Normal 1-day-old infant may have P02 as low as $60 \mathrm{mmHg}$, but transcutaneous oxygen saturation is higher than $90 \%$.

\subsection{Electrocardiographraphy}

1. The normal ECG of a newborn infant is different from that of a child or an adult as follows:

a. Sinus tachycardia with a rate as high as 180 beats $/ \mathrm{min}$.

b. A rightward QRS axis with a mean of +125 degrees and a maximum of +180 degrees.

c. Relatively small voltages for the QRS complex and the T wave.

d. RV dominance with tall $\mathrm{R}$ waves in the RPLs (V4R, V1, and V2).

e. Occasional q waves in V1(seen in about $10 \%$ of normal neonates)

f. Benign arrhythmias 
2. An abnormal ECG may be in the form of an abnormal P axis, abnormal QRS axis, hypertrophy of the ventricles or atria, vantricular conduction disturbances, or arrhythmias. Because of the wide ranges of normal values, many newborn infants with significant CHDs may show a normal ECG for their age. Arrhythmias in neonates are discussed later in this chapter.

a. P axis

1. A P axis in the right lower quadrant ( +90 to +180 degrees) suggests atrial situs inversus, asplenia syndrome, or incorrectly placed ECG electrodes.

2. A superor $\mathrm{P}$ axis suggests an ectopic atrial rhythm, as seen in polysplenia syndrome.

b. QRS axis

1. A superiorly oriented QRS axis between 0 and -150 degrees ( left anterior hemiblock) suggests partial or complete ECD, including splenic syndromes, or tricuspid atresia.

2. A QRS axis less than +30 degrees is abnormal and indicates left axis deviation (LAD) in the neonate. The QRSetween +30 and +60 degrees is unusual and indicates relative LAD.

3. A QRS axis greater than +180 degrees (in the range of -150 to -180 degrees) may indicate RAD.

c. Left ventricular hypertrophy $(\mathrm{LVH})$ is suggested in the newborn infant when the following are present:

1. Left atrial hypertrophy (LAD) or relative LAD (less than +60 degrees) for the neonate.

2. An R/S progression in the precordial leads that resembles the adult R/S progression.

3. QRS voltages demonstrating abnormal leftward and posterior forces or abnormal inferior forces for age

d. Right ventricular hypertrophy $(\mathrm{RVH})$ is difficult to diagnose because of the normal dominance of the RV at this age. However, the following are helpful clues to RVH in the newborn infant.

1. S waves in lead $\mathrm{I} 12 \mathrm{~mm}$ or greater

2. Pure $\mathrm{R}$ waves with no $\mathrm{S}$ waves in $\mathrm{V} 1$ greater than $10 \mathrm{~mm}$.

3. $\mathrm{R}$ waves in $\mathrm{V} 1$ greater than $25 \mathrm{~mm}$ or $\mathrm{R}$ waves in aVR greater than $8 \mathrm{~mm}$.

4. A qR pattern in $\mathrm{V} 1$ ( this is also seen in $10 \%$ of normal neonates).

5. Upright $\mathrm{T}$ waves in V1 after 3 days of age.

6. Right axis deviation (RAD) with the QRS axis greater than +180 degrees.

e. Atrial hypertrophy

1. Right atrial hypertrophy (RAH) is present when the $\mathrm{P}$ wave amplitude is greater than $3 \mathrm{~mm}$ in any lead.

2. Left atrial hypertrophy (LAH) iswhen the $\mathrm{P}$ wave duration is $0.08 \mathrm{sec}$ or greater (usually with notched $\mathrm{P}$ waves in the limb leads and biphasic $\mathrm{P}$ waves in $\mathrm{V} 1)$.

f. Ventricular conduction disturbances ( i.e, right bundle branch block (RBBB),left bundle branch block (LBBB), Wolff-Parkinson-Wite (WPW) syndrome, and intraventricular block)are present when the QRS duration is $0.07 \mathrm{sec}$ or more ( not $0.1 \mathrm{sec}$ or greater as in the adult) 
1. RBBB may be associated with Ebstein anomaly and COA in the newborn. It is sometimes seen in otherwise normal neonates.

2. LBBB is extremely rare in the newborn infant.

3. Intraventricular block ( with a widening of the QRS complex throughout the QRS duration) is more significant than RBBB because it is often associated with significant metabolic abnormalities (e.g., hypoxia, acidosis, hyperkalemia) and diffuse myocardial diseases.

4. WPW syndrome may be an isolated finding or may be associated with CHDs such as Ebstein anomaly or L-TGA. It is a frequent cause of SVT.

\subsection{Chest roentgenography}

1. Normal CXR findings

a. The cardiothoracic (CT) ratio of normal newborn infants may be greater than 0.5 because of inadequate inspiration and a large thymic shadow.

b. The thymic shadow may have any of several shapes, including a classic sail sign, or may have undulant or smooth borders, either unilateral or bilateral, on the upper mediastinum.

c. Cardiac silhouette is not always as well defined in neonates as in older children.

d. Evaluation of pulmonary vascular markings in the neonate poses a special problem. Although a reduced PBF is usually easier to detect (and indicates serious cyanotic CHD), increased vascularity is not always apparent even when the pulmonary blood flow is large. The distinction between increased PBF and pulmonary venous congestion is often difficult.

2. Abnormal chest $x$-ray findings: A cardiac problem is suggested by an abnormal size, position, or silhouette of the heart, by an abnormal shape or position of the liver, and by increased or decreased pulmonary vascularity on CXR films.

a. Heart size

The CT ratio is of limited value, since that of normal neonates is usually greater than 0.5. Many serious CHDs that eventually result in cardiomegaly show a normal heart size in neonates. Unequivocal cardiomegaly may be due to $\mathrm{CHD}$ (such as ventricular septal defect (VSD), PDA, transposition of the great arteries (TGA), Ebstein anomaly, hypoplastic left heart syndrome (HLHS), and other), myocarditis or cardiomyopathy, pericardial effusion, metabolic disturbance (e.g., hypoglycemia, severe hypoxemia, and acidosis), and overhydration or overtransfusion.

In the newborn infant who is intubated and on a ventilator, the heart size is greatly influenced by the ventilator setting. For example, a premature infant with a large-shunt PDA may have a normal-sized heart on chest $x$-ray film if the ventilator settings are high, especially the positive end-expiratory pressure.

b. Abnormal cardiac silhouettes may be of considerable help in suggesting the correct diagnosis.

1. A boot-shaped heart (coeur en sabot) is seen in tetralogy of Fallot (TOF) and in tricuspid atresia.

2. An egg-shaped heart with narrow waist may be seen in TGA.

3. A large, globular heart is seen in Ebstein anomaly. 
c. Dextrocardia or mesocardia

The presence of dextrocardia or mesocardia does not always indicate a serious heart defect. The segmental approach should be used for further evaluation. Four common situations seen in dextrocardia or mesocardia are situs inversus totalis with a normal heart, a rightward displacement of a normallyformed heart due to hypoplasia of the right lung, a complex cyanotic CHD, and asplenia or polysplenia syndrome.

d. The situs of abdominal viscera: A left-sided liver with the heart in the right side of the chest is seen in situs inversus totalis with normal heart. The liver and the cardiac apex on the same side suggest a complex cyanotic CHD. A midline liver suggests asplenia or polysplenia syndrome.

e. Pulmonary vascular markings

1. Increased pulmonary vascular marking (PVM) in a cyanotic infant suggest TGA, persistent truncus arteriosus, or single ventricle. In an acyanotic infant, increased PVMs suggest VSD, PDA, or endocardial cushion defect (ECD).

2. Decreased PVMs suggest a critical cyanotic CHD with decreased pulmonary blood flow(PBF), such as pulmonary atresia, tricuspid atresia, mor TOF with severe pulmonary stenosis or atresia.

3. A ground-glass appearance or a reticulated pattern of the lung fields is characteristic of pulmonary venous obstruction.

\section{Suggested approach to neonates with central cyanosis}

a. Although a significant heart murmur usually suggests a cardiac basis for the cyanosis, several of the more severe cardiac defects (transposition of the great vessels) may not initially be associated with a murmur.

Heart murmurs.

1. Innocent heart murmurs: More than $50 \%$ of full-term newborn infants ( and a higher percentage of premature infants) have an innocent systolic murmur at some time during the first week of life. Infants with innocent heart murmurs have normal ECG and chest x-ray findings. The four most common innocent murmurs in the newborn period are as follows:

a. Pulmonary flow murmur is most common. It is more often found in premature and small-for-gestational-age infants than in full-term infants. A soft systolic murmur ( grade 1 to 2/6), heard best at the upper left sternal border (ULSB), transmits well to bozh sides of the chest, axillae, and the back.

b. Transient systolic murmur of PDA is soft (grade 1 to 2/6), audible at the ULSB and in the left infraclavicular area on the first day. It usually disappears shortly thereafter.

c. Transient systolic murmur of tricuspid regurgitation is indistinguishable from that of VSD and is most common in infants who had fetal distress or neonatal asphyxia.

d. Vibratory systolic innocent murmur is a counterpart of Still's murmur in older children. It is audible at the LLSB, apex, or midprecordium.

2. Pathologic heart murmurs: Most pathologic murmurs except atrial septal defect (ASD) are audible during the first month of life. The time of appearance of a murmur depends on the nature of the defect. 
a. Heart murmurs of stenotic lesions (e.g., aortal stenosis (AS), pulmonary stenosis (PS)) are audible immediately after birth and persist, because they are independent of the level of the PVR.

b. Heart murmurs of L-R shunt lesions, especially those of a large VSD, may appear later, when the PVR decreases. The murmur of ASD appears late in infancy or in childhood.

c. The continuous murmur of a large PDA may not appear for 2 to 3 weeks. Instead, it is a crescendo systolic murmur with a slight or no diastolic component.

Even in the absence of a murmur, a newborn infant may have a serious heart defect that requires immediate attention, e.g., severe cyanotic heart disease such as TGA or pulmonary atresia with a closing PDA. Infants who are in severe CHF may not have a loud murmur until the myocardial function is improved with anticongestive measures.

b. Chest x-ray films may reveal pulmonary causes of cyanosis and urgency of the problem. They will also hint at the presence and the type of any cardiac defects.

c. Arterial blood gases on room air will confirm or rule out central cyanosis. Elevated Pco2 suggests pulmonary or central nervous system (CNS) problems. Low $\mathrm{pH}$ may be seen in sepsis, circulatory shock, or severe hypoxemia.

d. Hyperoxia test is one method of distinguishing cyanotic congenital heart disease from pulmonary disease. Neonates with cyanotic congenital heart disease usually do not have significantly raised arterial Pao2 during administration of $100 \%$ oxygen. If the Pao2 rises above $150 \mathrm{mmHg}$ during 100\% oxygen administration, an intracardiac shunt can usually be excluded, although the Pao2 of some patients with cyanotic congenital heart lesions may be transiently increased to greater than $150 \mathrm{~mm} \mathrm{Hg}$ because of intracardiac streaming patterns. The Pao2 in patiens with pulmonary disease generally increases significantly as ventilation - perfusion inequalities are overcome by oxygen administration. In infants with a CNS disorder, the Pao2 completely normalizes during artificial ventilation. Hypoxia in many heart lesions is profound and constant, whereas in respiratory disorders and in primary hypertension of the neonate (PPHN), arterial oxygen tension is not as low and often varies with time or changes in ventilator management. Hyperventilation may improve the hypoxia in neonates with PPHN and only occasionally in those with cyanotic heart disease.

e. An ECG should be obtained if a cardiac origin of cyanosis is suspected.

f. Two-dimensional echocardiography is the definitive noninvasive test to determine the presence of congenital heart disease. The information obtained is essential in avoiding unnecessary cardiac catheterization and angiography in the absence of a cardiac defect, as well as in making a specific diagnosis.

g. Umbilical artery line: A Po2 value in a preductal artery ( such as right radial artery) higher than that in a postductal artery (umbilical artery line) by 10 to $15 \mathrm{~mm} \mathrm{Hg}$ suggests an R-L shunt through a PDA. Such a differential Po2 level may result from persistent pulmonary hypertension of the newborn (PPHN), critical AS, interrupted aortic arch, or coarctation of the aorta. An echo study will clarify the cause of the differential Po2 levels.

h. Cardiology consultation is called for if a cardiac origin of cyanosis is suspected. 


\section{Heart failure in the newborn infant}

The clinical picture of CHF in the neonate may simulate another disorder such as meningitis, sepsis, pneumonia, or bronchiolitis. Tachypnea, tachycardia, pulmonary crackles or rhonchi, hepatomegaly, and weak peripheral pulses are common presenting signs. Heart murmur is either faint or absent. Cardiomegaly on chest x-ray film is always present, with or without increased PVMs or pulmonary edema. Causes of CHF in the neonate are listed in Table 2.

\section{a. Structural heart defects}

At birth

Hypoplastic left heart syndrome (HLHS)

Severe tricuspid or pulmonary regurgitation

Large systemic AV fistula

Week 1

TGA

Large PDA in premature infant

Total anomalous pulmonary venous return (TAPVR) below diaphragm

Week $1-4$

Critical AS or PS

Preductal COA

b. Noncardiac causes

1. Birth asphyxia (resulting in transient myocardial ischemia)

2. Metabolic: hypoglycemia, hypocalcemia

3. Severe anemia (as seen in hydrops fetalis)

4. Neonatal sepsis

5. Overtransfusion or overhydration

c. Myocardial disease

1. Myocarditis

2. Transient myocardial ischemia (with or without birth asphyxia)

3. Catdiomyopathy ( seen in infants of diabetic mothers)

d. Disturbances in heart rate

1. Supravetricular tachycardia (supraventricular tachycardia (SVT) or paroxysmal atrial tachycardia(PAT))

2. Atrial flutter or fibrillation

3. Congenital heart block ( when associated with CHD)

The time of onset of CHF varies rather predictably with the type of CHD.

Table 2. Cause of heart failure in the neonate

Two important CHDs that present with CHF in the newborn period are hypoplastic left heart syndrome (HLHS) and large PDA in premature infants. Transient myocardial ischemia and infants of diabetic mothers are other causes of CHF in the neonate.

\section{Hypoplastic left heart syndrome}

a. Prevalence:HLHS occurs in $1 \%$ of all CHDs and is the most common cause of death from CHD during the first month of life.

b. Pathology and pathophysiology 
1. HLHS includes a group of closely related anomalies characterized by hypoplasia of the left ventricul (LV) (from atresia or severe stenosis of the aortic and/or mitral valves) and hypoplasia of the ascending aorta and aortic arch. The LA is small, and the atrial septum is frequently intact other than the PFO.

2. During fetal life the pulmonary vascular resistance (PVR) is higher than the systemic vascular resistance (SVR), and the dominant RV maintains normal perfusing pressure in the descending aorta through the ductal R-L shunt, even in the presence of the nonfunctioning hypoplastic LV. However, difficulties arise after birth, primarily from two factors: (1) reversal of the vascular resistance in the two circuits with the SVR higher than the PVR, and (2) closure of the PDA. The end result is a marked decrease in systemic cardiac output and aortic pressure, resulting in circulatory shock and metabolic acidosis. An increase in PBF in the presence of the nonfunctioning LV results in an elevated LA pressure and pulmonary edema.

c. Clinical manifestations

1. The neonate is critically ill in the first few hourse to days of life, with mild cyanosis, tachycardia, tachypnea, and pulmonary crackles.

2. Poor peripheral pulses and vasoconstricted extremities are characteristic. The S2 is loud and single. Heart murmur is usually absent, but a grade 1 to $3 / 6$ ejection systolic murmur may be present over the precordium.

3. The ECG shows RVH. Rarely, left ventricular hypertrophy (LVH) pattern is present because V5 and V6 electrodes are placed over the dilated RV.

4. Chest x-ray films show pulmonary venous congestion or pulmonary edema. The heart is only mildly enlarged.

5. The arterial blood gas determination reveals severe metabolic acidosis in the presence of a slightly decreased Po2, a characteristic finding of this condition.

6. Echo findings are diagnosticand usually obviate cardiac catheterization. Severe hypoplasia of the aorta and aortic annulus and the absent or distorted mitral valve are usually imaged. The LV cavity is diminutive. The RV cavity is markedly dilated, and the tricuspid valve is large.A partially constricted PDA may be imaged.

7. Progressive hypoxemia and acidosis result in death, usually in the first month of life.

d. Management

1. Preoperatively the goal is to achieve adequate systemic oxygen delivery. Patency of the ductus arteriosus is critical for survival until surgery. Blood flow to the pulmonary and systemic circulations should be nearly balanced (goal p/s ratio of 1). The immediate therapy for all infants with HLHS is an intravenous infusion of prostaglandin E1 (PGE1) in order to pharmacologically manipulate the ductus arteriosus (DA) and maintain ductal patency. A continuous infusion of the prostaglandin is initiated, preferably through a central catheter, at a rate of 0.05 to $0.1 \mu \mathrm{g} / \mathrm{kg}$ per minute. However, numerous side effects are associated with PGE1 infusion such as respiratory depression, fever, lethargy, irritability, myoclonic jerks, flushing, edema, pyloric stenosis, hyperostosis, necrotizing enetrocolitis, as well as structural remodeling of the DA and the pulmonary vessels, with a reported incidence of these complications ranging from 10 to $40 \%$. $(7,8)$ In the future 
Sildenafil could be a reasonable alternative to PGE1 for maintaining DA patency, since it can also prevent and reverse DA closure through a mechanism that is distinct, and eventually safer, from the PGE1 mechanism. (9) An audible murmur and adequate peripheral perfusion provide evidence of ductal patency; however, Doppler echocardiography is needed to confirm flow. Once the ductus is open, the rate of infusion may be reduced to decrease the risk for potential adverse effects. Unrestricted blood flow through the ductus arteriosus is necessary for systemic perfusion. Sometimes even a temporary discontinuation of the prostaglandin infusion is possible, with careful monitoring of blood pressure and urine volume as well as frequent echocardiographic examinations, in order to enable maintenance of balance between systemic and pulmonary blood flow. (4)

The pulmonary/systemic $(\mathrm{p} / \mathrm{s})$ ratio preoperatively is dictated by the adequacy of the interatrial communication. An infant with a mildly restrictive interatrial communication may have balanced circulation and remain in a clinically stable condition as long as the ductus arteriosus remains open. Oxygen saturations of $75 \%$ to $85 \%$ by pulse oximetry suggest adequate balance between systemic and pulmonary blood flow. Ventilatory support may be needed for apneic episodes or tenacious secretions, both common adverse effects of treatment with prostaglandin E1. Judicious use of inotropic support is initiated if evidence of low cardiac output is detected. Infusion of dopamine at a rate of 3 to $5 \mu \mathrm{g} / \mathrm{kg}$ per minute usually results in improved ventricular function. High-dose inotropic support should be used with caution because it can result in increased SVR and cause a shift in the $\mathrm{p} / \mathrm{s}$ ratio to greater than 1 . In our institution we do not recommend the use of dopamine as a "standard" since we consider it a "dirty" drug with a lot of potential unexpected effects. Diuretics may be necessary to help alleviate the increased volume load on the right ventricle.

Infants with an unrestrictive inter-atrial communication may be in a stable condition initially, but signs of congestive heart failure may develop as the PVR (pulmonary vascular resistance) decreases. When oxygen saturations are approximately 90\%, systemic blood flow may be reduced, resulting in tissue hypoperfusion, metabolic acidosis, and a low cardiac output state. In infants with high oxygen saturation and evidence of tissue hypoperfusion, controlled mechanical ventilation is often initiated to improve the $\mathrm{p} / \mathrm{s}$ ratio and systemic cardiac output.

Severe tricuspid regurgitation (TR) could be another issue that complicates the life of the intensivist dealing with a newborn with HLHS. Good preoperative management with mechanical ventilation in order to lower the degree of TR results in a better short-term prognosis of stage 1 Norwood operation. (4)

The goal of respiratory management is to increase pulmonary vascular resistance and decrease systemic vascular resistance. The $\mathrm{p} / \mathrm{s}$ ratio can be manipulated by increasing PVR by increasing the $\mathrm{PaCO} 2 . \mathrm{PaCO} 2$ can be increased by adding supplemental inspired carbon dioxide, a potent pulmonary vasoconstrictor, to the ventilator circuit. This approach for increasing $\mathrm{PaCO} 2$ is preferred over hypoventilation, which may lead to atelectasis. PVR can also be increased by decreasing the concentration of inspired oxygen by adding supplemental nitrogen 
gas to attain a fraction of inspired oxygen of 0.17 to 0.19 . PVR can also be increased by maintaining the hematocrit at greater than 0.40 , a state that optimizes oxygencarrying capacity and increases the viscosity of the blood. Although these medical management strategies may provide temporary palliation, infants with marked pulmonary overcirculation and systemic hypoperfusion benefit from early surgical correction, because the methods to reverse this situation have limited effectiveness. Infants with HLHS who are born with a severely restricted or no inter-atrial communication, a rare occurrence, have profound hypoxemia. In fact, morbidity and mortality remain high in the subset of patients with an intact or very restrictive atrial septum. (10) The severe restriction of blood flow across the atrial septum results in a life-threatening situation and these patients, which present with severe cyanosis and hemodynamic instability, require urgent postnatal cardiac catheterization to relieve the septal obstruction and improve oxygenation. (11) Relief of the obstruction can be achieved by a balloon atrial septostomy or blade septostomy at the time of cardiac catheterization or a surgical atrial septectomy. The tenuous condition of these infants makes each of these interventions high risk. The choice of intervention depends on the severity of the obstruction, the infant's cardiac anatomy and physiology, and the experience of the available medical and surgical team.

2. Surgical: Three options are available in the management of these infants:do nothing or choose one of two surgical options. The surgical options are the Norwood operation (followed by a Fontan operation) and cardiac transplantation. The surgical procedure of choice remains controversial.

1. Norwood operation

a. The first-stage Norwood operation is performed on the neonate. This operation consists of (1) division of the MPA and closure of the distal stump, (2) a right-sided Gore-Tex shunt (usually a 4-mm tube) to provide $\mathrm{PBF},(3)$ excision of the atrial septum ( for adequate interatrial mixing), and (4) construction of a new aortic arch between the proximal main pulmonary artery (MPA) and the hypoplastic ascending aorta and aortic archm using an aortic or pulmonary artery allograft. The surgical mortality rate is $35 \%$ or higher.

b. A cavopulmonary shunt ( or bidirectional Glenn operation) is carried out at 6 months of age. Mortality is less than $5 \%$.

c. A modified Fontan operation is carried out when the patient is a year and a half old. Overall survival after the Fontan operation is about $50 \%$ at 4 years.

2. Cardiac transplantation is considered to be the procedure of choice in some centers. The transplantation is not a cure for the defect but creates a lifelong medical problem, the threat of infection and rejection.

\section{Premature neonates with a large PDA}

a. Prevalence.

Significant PDA with CHF occurs in 15\% of prematures with a birth weight of less than $1,750 \mathrm{~g}$ and in $40 \%$ to $50 \%$ of those with a birth weight of less than $1,500 \mathrm{~g}$. 
b. Pathophysiology

This is a special problem in premature infants who have been recovering from hyaline membrane disease. With improvement in oxygenation the PVR drops rapidly, but the ductus remains patent because its responsiveness to oxygen is immature in the premature newborn infant. The resulting large L-R ductal shunt makes the lungs stiff, and weaning the infant from ventilator and oxygen therapy becomes difficult. Infants who remain on ventilators for a long time develop bronchopulmonary dysplasia with resulting pulmonary hypertension ( cor pulmonale) and right-sided heart failure.

c. Clinical manifestations

1. The history usually reveals that a premature infant with hyaline membrane disease has made some improvement during the first few days after birth, but this is followed by inability to wean the infant from the ventilator or a need to increase ventilator settings or oxygen requirement in 4-to 7-day-old premature infants. Apneic spells or episodes of bradycardia may be initial signs in infants who are not on ventilators.

2. Bounding peripheral pulses and a hyperactive precordium are usually present. The classic continuous murmur of PDA at the ULSB is diagnostic, but the murmur is sometimes systolic only at the middle and upper LSB. Premature infants who are fluid overloaded or retaining fluid may also present with the hyperdynamic precordium, an ejection systolic murmur, bounding pulse, and wide pulse pressure.

3. The ECG is usually normal.

4. Chest x-ray films show cardiomegaly and evidence of pulmonary edema or pulmonary venous congestion in addition to varying degrees of the lung disease.

5. 2D echo study confirms the diagnosis. It provides anatomic information about the diameter, length, and shape of the ductus. The Doppler study of the ductus ( with the sample volume placed at the pulmonary end of the ductus) provides important functional information such as ductal shunt patterns ( pure L-R, bidirectional, or predominant R-L shunt), pressure in the PA, and magnitude of the ductal shunt or pulmonary perfusion status. An indirect estimate of the magnitude of the shunt can be made by the LA and LV dimensions.

d. Management: For symptomatic infants, either pharmacologic ( indomethacin) or surgical closure of the ductus is indicates. A small PDA that is not causing CHF should be followed up medically for 6 months without surgical ligation because of the possibility of spontaneous closure.

1. Indomethacin (a prostaglandin synthetase inhibitor), $0.2 \mathrm{mg} / \mathrm{kg}$ IV every 12 hours for up to three doses, may be used on selected cases. A second course is occasionally necessary for adequate ductal closure. Contraindications to the use of indomethacin include (1) BUN over $25 \mathrm{mg} / \mathrm{dL}$ or creatinine levels over $1.8 \mathrm{mg} / \mathrm{dL}$, (2) a platelet count below $80,000 / \mathrm{mm}^{3}$, (3) a bleeding tendency ( including intracranial hemorrhage), (4) necrotizing enterocolitis, and (5) hyperbilirubinemia.

2. A European study showed that ibuprofen given IV ( $10 \mathrm{mg} / \mathrm{kg}$ followed by 5 $\mathrm{mg} / \mathrm{kg}$ every 24 hours, two times), starting on the 3rd day of life, was as effective as indomethacin ( $0.2 \mathrm{mg} / \mathrm{kg}$ IV every 12 hours, three times), with a lower incidence of oliguria and a less deleterious effect on the cerebral blood flow than indomethacin. However, ibuprofen is not approved for use in premature PDA in this country. 
3. If the medical treatment is unsuccessful or if the use of indomethacin is contraindicated, a surgical ligation of the ductus is indicated. The standard operative approach to the PDA has been through a posterolateral thoracotomy. The safety, effectiveness, and minimally invasive nature of video-assisted thoracoscopic surgery (VATS) have been reported for premature PDA. Advantages of the technique may include no need to cut the muscle and to spread ribs, thus a reduced compromise of respiratory mechanics and of chest wall deformity.

\section{Persistent pulmonary hypertension of the newborn}

\section{(Persistent Fetal Circulation)}

PPHN occurs in term and post-term infants. Predisposing factors include birth asphyxia, meconium aspiration pneumonia, early-onset sepsis, hypoglycemia, polycythemia, maternal use of nonsteroidal anti-inflammatory drugs with in utero constriction of the ductus arterious, and pulmonary hypoplasia as a result of diaphragmatic hernia, amniotic fluid leak, oligohydramnions, or pleural effusions. PPHN is often idiopathic. Some patients with PPHN have low plasma arginine and nitric oxide metabolite concentrationsand polymorphisms of the carbamoyl phosphate synthase gene, findings suggestive of a possible subtle defect in nitric oxide production. The incidence is $1 / 500-1,500$ live births with a wide variation between different clinical centers.

a. Pathophysiology: Persistence of the fetal circulatory pattern of right-to-left shunting through the PDA and foramen ovale after birth is due to excessively high pulmonary vascular resistance. Fetal pulmonary vascular resistance is usually elevated relative to fetal systemic or postnatal pulmonary pressure. This fetal state permits shunting of oxygenated umbilical venous blood to the left atrium (and brain) through the foramen ovale and bypasses the lungs through the ductus arterious to the descending aorta. After birth, pulmonary vascular resistance normally declines rapidly as a consequence of vasodilation secondary to gas filling the lungs, a rise in postnatal $\mathrm{Pao} 2$, a reduction in Pco2, increased $\mathrm{pH}$, and release of vasoactive substances. Increased neonatal pulmonary vascular resistance may (1) be maladaptive from an acute injury (e.g., not demonstrating normal vasodilation in response to increased oxygen and other changes after birth); (2) be the result of increased pulmonary artery medial muscle thickness and extension of smooth muscle layers into the usually nonmuscular, more peripheral pulmonary arterioles in response to chronic fetal hypoxia; (3) be due to pulmonary hypoplasia ( diaphragmatic hernia, Potter syndrome); (4) be obstructive as a result of polycythemia or total anomalous pulmonary venous return; or (5) be due to alveolar capillary dysplasia, a lethal, possibly familial disorder characterized by a thickened alveolar septum and a reduced number of small pulmonary arteries and capillaries. Apart from the etiology, profound hypoxia from right-to-left shunting and normal or elevated Pco2 are present.

b. Clinical Manifestations: Infants become ill in the delivery room or within the first $12 \mathrm{hr}$ of life. PPHN related to polycythemia, idiopathic causes, hypoglycemia, or asphyxia may result in severe cyanosis with tachypnea, although initially, signs of respiratory distress may be minimal. Infants who have PPHN associated with meconium aspiration, group B streptococcal pneumonia, diagphragmatic hernia, or pulmonary hypoplasia usually exhibit cyanosis, grunting, flaring, retractions, tachycardia, and 
shock. Multiorgan involvement may be present. Myocardial ischemia, papillary muscle dysfunction with mitral and tricuspid regurgitation, and cardiac stunning produce cardiogenic shock with decreased pulmonary blood flow, tissue perfusion, and oxygen delivery. The hypoxia is quite labile and often out of proportion to the findings on chest roentgenograms.

c. Diagnosis: PPHN should be suspected in all term infants who have cyanosis with or without fetal distress, intrauterine growth restriction, meconium-stained amniotic fluid, hypoglycemia, polycythemia, diaphragmatic hernia, pleural effusions, and birth asphyxia. Hypoxia is universal and is unresponsive to $100 \%$ oxygen given by oxygen hood, but it may respond transiently to hyperoxic hyperventilation administered after endotracheal intubation or to the application of a bag and mask. A Pao2 gradient between a preductal (right radial artery) and a postductal (umbilical artery) site of blood sampling greater than $20 \mathrm{~mm} \mathrm{Hg}$ suggest right-to-left shunting through the ductus arteriosus. Real-time echocardiography combined with Doppler flow studies demonstrates right-to-left shunting across a patent foramen ovale and a ductus arteriosus. Deviation of the intraatrial septum into the left atrium is seen in severe PPHN. Tricuspid or mitral insufficiency may be noted on auscultation as a holosystolic murmur and can be visualized echocardiographically together with poor contractility when PPHN is associated with myocardial ischemia. The degree of tricuspid regurgitation can be used to estime pulmonary artery pressure. The 2nd heart sound is accentuated and not split. In asphyxia-associated and idiopathic PPHN, the chest roentgenogram is normal, whereas in PPHN associated with pneumonia and diaphragmatic hernia, it shows the specific lesions of parenchymal opacification and bowel in the chest, respectively. The differential diagnosis of PPHN includes cyanotic heart disease (especially obstructed total anomalous pulmonary venous return) and the associated etiologic entities that predispose to PPHN (e.g., hypoglycemia, polycythemia, sepsis).

d. Treatment: Therapy is directed toward correcting any predisposing disease ( hypoglycemia, polycithemia) and improving poor tissue oxygenation. The response to therapy is often unpredictable, transient, and complicated by the adverse effects of drugs or mechanical ventilation. Initial management includes oxygen administration and correction of acidosis, hypotension, and hypercapnia. Persistent hypoxia should be managed with intubation and mechanical ventilation.

Treatment with inhaled nitric oxide (iNO) is indicated for newborns with an oxygen index (OI) of less than 25. Nitric oxide (NO) is an endothelially derived gas signaling molecule that relaxes vascular smooth muscle and that can be delivered to the lung by means of an inhalation device. In 2 large, randomized trials, NO reduced the need for extracorporeal membrane oxygenation (ECMO) by approximately $40 \%$. Although these trials led to the US Food and Drug Administration (FDA) approving iNO as a therapy for persistent pulmonary hypertension of the newborn (PPHN), iNO did not reduce mortality, the length of hospitalization, or the risk of neurodevelopmental impairment. A randomized study confirmed that beginning iNO at a milder or earlier point in the disease course (for an oxygenation index of 15-25) did not decrease the incidence of ECMO and/or death or improve other patient outcomes, including the incidence of neurodevelopmental impairment.The use of iNO has not been demonstrated to reduce the need for ECMO in newborns with congenital 
diaphragmatic hernia. In these newborns, iNO should be used in non-ECMO centers to allow for acute stabilization, followed by immediate transfer to a center that can provide extracorporeal membrane oxygenation (ECMO).Contraindications to iNO include congenital heart disease characterized by left ventricular outflow tract obstruction (eg, interrupted aortic arch, critical aortic stenosis, hypoplastic left heart syndrome) and severe left ventricular dysfunction. The appropriate starting dose is 20 ppm. Doses higher than this have not been shown to be more effective and have been associated with adverse effects, including methemoglobinemia and increased levels of nitrogen dioxide $\left(\mathrm{NO}_{2}\right)$.Appropriate lung recruitment and expansion are essential to achieve the best response. If a newborn has severe parenchymal lung disease and PPHN, strategies such as HFV may be required.Most newborns require iNO for less than 5 days. In general, the dose can be weaned to 5 ppm after 6-24 hours of therapy. The dose is then slowly weaned and discontinued when the $\mathrm{FiO}_{2}$ is less than 0.4-0.6 and the iNO dose is $1 \mathrm{ppm}$. Abrupt discontinuation at higher doses should be avoided because it may cause abrupt rebound pulmonary hypertension. In centers that do not have immediate availability of ECMO support, use of iNO must be approached with caution. Because iNO cannot be abruptly discontinued, transport with iNO is usually needed if a subsequent referral for ECMO is necessary. This capability should be determined in collaboration with the ECMO center before treatment is started. The use of iNO with high frequency ventilation (HFV) creates particular problems for transport, and this should be considered before these therapies are combined in a non-ECMO center.

ECMO, an adaptation of cardiopulmonary bypass, is used when optimal support fails to maintain acceptable oxygenation and perfusion. The introduction of ECMO and other new therapies has had a major effect on reducing the mortality rate associated with PPHN. ECMO support can now be provided using a double-lumen catheter in the internal jugular vein; thus, ligation of the right common carotid artery can be avoided. Although iNO is an effective pulmonary vasodilator, ECMO remains the only therapy that has been proven to be life-saving for PPHN. Therefore, timely transfer to an ECMO center is vital for newborns with severe PPHN.However, it is often difficult to determine the proper timing of a referral to an ECMO center. Referral and transfer should occur before refractory hypoxemia develops. Early consultation and discussion with clinicians at the ECMO center is strongly recommended. Continuous delivery of $\mathrm{NO}$ is required during transport. Baseline criteria for newborns considered for ECMO are generally as follows:

- Gestation of more than 34 week

- Weight more than $2000 \mathrm{~g}$

- No major intracranial hemorrhage on cranial sonograms (ie, larger than a grade II hemorrhage)

- Reversible lung disease or mechanical ventilation for 7-14 days

- No evidence of lethal congenital anomalies or inoperable cardiac disease

\section{Transient myocardial ischemia}

a. Prevalence

Transient myocardial ischemia is a rarely recognized condition; the prevalence is unknown. 
b. Pathology and pathophysiology

1. Subendocardial ischemia or necrosis ( possibly secondary to hypoxic pulmonary vasoconstriction) occurs in the papillary muscles and other areas of the ventricles in the newborn infant who had prenatal or perinatal hypoxia and distress. Evidence of pulmonary hypertension, bidirectional shunts at the atrial and/or ductal levels, and TR are usually present. Variable degrees of LV dysfunction are demonstrable by echocardiography.

2. Three levels of severity have been recognized.

a. Transient tachypnea of the newborn is the mildest form of the condition. Mild LV dysfunction leads to fluid retention, pulmonary edema, and reduced lung compliance producing tachypnea.

b. Transient tricuspid ( or mitral) regurgitation results from papillary muscle infarction ( evidenced by elevated serum levels of creatine phosphokinase MB fraction).

c. Severe CHF with cardiogenic shock is the most severe form of myocardial dysfunction seen in the newborn infant.

c. Clinical manifestations

1. Tachypnea develops usually in full-term neonates with a low Apgar score. Mild cyanosis may also be present.

2. A systolic murmur of TR or MR is commonly present. Rarely, CHF with gallop rhythm, hypotension, and vascular collapse result.

3. The ECG may show generalized flat $\mathrm{T}$ waves and minor ST segment depression. Abnormal $Q$ waves suggestive of anterior or inferior infarction may be seen.

4. CXR films show varying degrees, sometimes marked, of cardiomegaly. PVMs may be increased due to pulmonary venous congestion ( described as wet lung) in severely affected neonates.

5. Echo study reveals varying degrees of myocardial dysfunction, including an enlarged LA and / or LV, decreased contractility of the LV, and mitral regurgitation (MR).

6. Laboratory studies may reveal mild reduction of $\mathrm{Po} 2$ and $\mathrm{pH}$ ( but usually without $\mathrm{CO} 2$ retention), hypoglycemia, and elevated $\mathrm{CPK} \mathrm{MB}$ fraction in patients with significant TR. A myocardial perfusion scan may show a diffuse impairment of thallium-201 uptake (different from myocarditis, in which myocardial perfusion is normal).

7. Infants with transient myocardial ischemia usually recover unless it is associated with severe acidosis, CNS damages, or advanced sepsis.

d. Management

1. Supportive measures with administration of oxygen, correction of acidosis, and treatment of hypogycemia are all that are required for mild cases.

2. For severely affected infants, ventilatory assistance, short-acting inotropic agents ( such as dopamine), a vasodilator agent, and fluid restriction and diuretic(s) may be indicated.

\section{Emergency treatment if cyanotic CHD is suspected}

If a cyanotic CHD is suspected, PGE1 should be started or made available. The starting dose is 0.05 to $0.1 \mu \mathrm{g} / \mathrm{kg} / \mathrm{min}$, administered in a continuous IV drip. When the desired effects 
(increased Po2, increased systemic blood pressure, and improved $\mathrm{pH}$ ) are achieved, the dose should be reduced step-by-step to $0.01 \mu \mathrm{g} / \mathrm{kg} / \mathrm{min}$. When there is no effect with the initial starting dose, it may be increased to $0.4 \mu \mathrm{g} / \mathrm{kg} / \mathrm{min}$.

If echocardiography is not immediately available, the clinician caring for a newborn with possible cyanotic heart disease should not hesitate to start a prostaglandin infusion ( for a possible ductal-dependent lesion). Because of the risk of hypoventilation associated with prostaglandins, a practitioner skilled in neonatal endotracheal intubation must be available. Three common side effects of Prostaglandin E1 IV infusion are apnea (12\%), fever (14\%), and flushing $(10 \%)$.

\section{Summary}

The evaluation of the cyanotic neonate should be done in an algorithmic manner that focuses on evaluation and management of the most life-threatening disease processes first.The hyperoxia test should be utilized early in the evaluation of these patients to assist in the differentiation and categorization of the cyanotic event. Be careful to obtain a detailed history of the prenatal, birth, and postnatal periods, as physicians will often be able to narrow the differential by the history alone. Neonates may decompensate very quickly, and preparations for a life-saving emergency should be made as soon as possible.

\section{References}

[1] Baba K, Ohtsuki S, Kamada M, Kataoka K, Ohno N, Okamoto Y, et al. Preoperative management for tricuspid regurgitation in hypoplastic left heart syndrome. Ped Internat 2009;51:399-404.

[2] Fricker FJ. Hypoplastic Left Heart Syndrome - Diagnosis and early management. NeoReviews 2008;9:253.

[3] Hoffmann GM, Ghanayem NS, Kampine JM, Berger S, Mussatto KA, Litwin SB, et al. Venous saturation and the anaerobic threshold in neonates after the Norwood procedure for hypoplastic left heart syndrome. Ann Thorac Surg 2000;70:1515-21.

[4] Singh GH, Fong LV, Salmon AP, Keeton BR. Study of low dosage prostaglandin - usages and complication. Eur Heart J 1994;15:377-81.

[5] Lewis AB, Freed MD, Heymann MA, Roehl SL, Kensey RC. Side effects of therapy with prostaglandin E1 in infants with critical congenital heart disease. Circulation 1981;64: 893-8.

[6] Thiebaud B, Michelakis E, Wu XC, Harry G, Hashimoto K, Archer SL. Sildenafil Reverses $\mathrm{O} 2$ constriction of the rabbit Ductus Arteriosus by inhibiting Type 5 phosphodisesterase and activating BK Ca Channels. Ped Res 2002;52:19-24.

[7] Rychik J, Rome JJ, Collins MH, DeCampli WM, Spray TL. The hypoplastic left heart syndrome with intact atrial septum: atrial morphology, pulmonary vascular histopathology and outcome. J Am Coll Cardiol 1999;34:554-60.

[8] Atz AM, Feinstein JA, Jonas RA. Preoperative management of pulmonary venous hypertension in hypoplastic left heart syndrome with restrictive atrial septal defect. Am J Cardiol 1999;83:1224-8. 
[9] Newburger JW, Jonas RA, Wernovsky G. A comparison of the preoperative neurologic effects of hypothermic circulatory arrest versus low-flow cardiopulmonary bypass in infant heart surgery. N Engl J Med 1993;329:1057-64.

[10] Miller SP, McQuillen PS, Hamrick S, Xu D, Glidden DV, Charlton N. Abnormal brain development in newborns with congenital heart disease. $N$ Engl J Med. 2007;357:1928-38.

[11] Tabbutt S, Nord AS, Jarvik GP. Neurodevelopmental outcomes after staged palliation for hypoplastic left heart syndrome. Pediatrics 2008;121:476-83.

[12] Dorfman AT, Marino BS, Wernovsky G, Tabbutt S, Ravishankar C, Godinez RI, et al. Critical heart disease in the neonate: Presentation and outcome at a tertiary care center. Pediatr Crit Care Med 2008;9:193-202

[13] Behrman RE, Kliegman RM, Jenson HB. Nelson Textbook of Pediatrics (17th edition). Philadelphia: W.B.Sauders, 2004

[14] Senka Mesihović- Dinarević. Dječija kardiologija: od fetusa do adolescenta. Medicinski fakultet, Sarajevo; 2000

[15] Gomella TL. Neonatology: Management, Procedures, On-Call Problems. Diseases, and Drugs (4th edition). Appleton \& Lange; 1999

[16] Chambers CD, Hernandez-Diaz S, Van Marter LJ, Werler MM, Louik C, Jones KL, et al. Selective serotonin-reuptake inhibitors and risk of persistent pulmonary hypertension of the newborn. N Engl J Med. Feb 9 2006;354(6):579-87. [Medline].

[17] Steinhorn RH, Kinsella JP, Pierce C, Butrous G, Dilleen M, Oakes M, et al. Intravenous sildenafil in the treatment of neonates with persistent pulmonary hypertension. $J$ Pediatr. Dec 2009;155(6):841-847.e1. [Medline].

[18] Bahrami KR, Van Meurs KP. ECMO for neonatal respiratory failure. Semin Perinatol. Feb 2005;29(1):15-23. [Medline].

[19] Farrow KN, Fliman P, Steinhorn RH. The diseases treated with ECMO: focus on PPHN. Semin Perinatol. Feb 2005;29(1):8-14.[Medline].

[20] UK collaborative randomised trial of neonatal extracorporeal membrane oxygenation. UK Collaborative ECMO Trail Group. Lancet. Jul 13 1996;348(9020):7582. [Medline].

[21] Shah PS, Ohlsson A. Sildenafil for pulmonary hypertension in neonates. Cochrane Database Syst Rev. Aug 10 2011;CD005494.[Medline].

[22] Walsh-Sukys MC, Tyson JE, Wright LL, Bauer CR, Korones SB, Stevenson DK, et al. Persistent pulmonary hypertension of the newborn in the era before nitric oxide: practice variation and outcomes. Pediatrics. Jan 2000;105(1 Pt 1):14-20. [Medline].

[23] Wung JT, James LS, Kilchevsky E, James E. Management of infants with severe respiratory failure and persistence of the fetal circulation, without hyperventilation. Pediatrics. Oct 1985;76(4):488-94. [Medline].

[24] Konduri GG, Solimano A, Sokol GM, Singer J, Ehrenkranz RA, Singhal N, et al. A randomized trial of early versus standard inhaled nitric oxide therapy in term and near-term newborn infants with hypoxic respiratory failure. Pediatrics. Mar 2004;113(3 Pt 1):559-64.[Medline].

[25] Steinhorn RH. Nitric oxide and beyond: new insights and therapies for pulmonary hypertension. J Perinatol. Dec 2008;28 Suppl 3:S67-71. [Medline]. [Full Text]. 
[26] Pawlik TD, Porta NF, Steinhorn RH, Ogata E, deRegnier RA. Medical and financial impact of a neonatal extracorporeal membrane oxygenation referral center in the nitric oxide era. Pediatrics. Jan 2009;123(1):e17-24. [Medline].

[27] Metra M, Giubbini R, Nodari S, et al. Differential effects of beta-blockers in patients with heart failure: A prospective, randomized, double-blind comparison of the long-term effects of metoprolol versus carvedilol. Circulation. Aug 1 2000;102(5):546-51. [Medline]. [Full Text].

[28] Rosenthal D, Chrisant MR, Edens E, et al. International Society for Heart and Lung Transplantation: Practice guidelines for management of heart failure in children. $J$ Heart Lung Transplant. Dec 2004;23(12):1313-33. [Medline].

[29] Shaddy RE. Optimizing treatment for chronic congestive heart failure in children. Crit Care Med. Oct 2001;29(10 Suppl):S237-40.[Medline].

[30] Shaddy RE, Tani LY, Gidding SS, et al. Beta-blocker treatment of dilated cardiomyopathy with congestive heart failure in children: a multi-institutional experience. J Heart Lung Transplant. 1999;18:269-74. [Medline].

[31] Taketomo CK, Hurlburt-Hodding J, Kraus DM. Pediatric drug handbook. 1997-1998. 


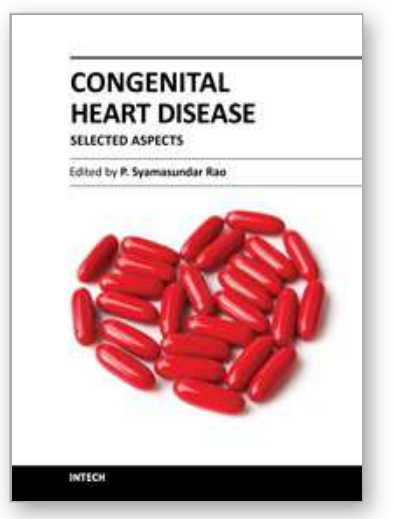

\author{
Congenital Heart Disease - Selected Aspects \\ Edited by Prof. P. Syamasundar Rao
}

ISBN 978-953-307-472-6

Hard cover, 348 pages

Publisher InTech

Published online 18, January, 2012

Published in print edition January, 2012

There are significant advances in the understanding of the molecular mechanisms of cardiac development and the etiology of congenital heart disease (CHD). However, these have not yet evolved to such a degree so as to be useful in preventing $\mathrm{CHD}$ at this time. Developments such as early detection of the neonates with serious heart disease and their rapid transport to tertiary care centers, availability of highly sensitive noninvasive diagnostic tools, advances in neonatal care and anesthesia, progress in transcatheter interventional procedures and extension of complicated surgical procedures to the neonate and infant have advanced to such a degree that almost all congenital cardiac defects can be diagnosed and "corrected". Treatment of the majority of acyanotic and simpler cyanotic heart defects with currently available transcatheter and surgical techniques is feasible, effective and safe. The application of staged total cavo-pulmonary connection (Fontan) has markedly improved the long-term outlook of children who have one functioning ventricle. This book, I hope, will serve as a rich source of information to the physician caring for infants, children and adults with CHD which may help them provide optimal care for their patients.

\title{
How to reference
}

In order to correctly reference this scholarly work, feel free to copy and paste the following:

Emina Hadzimuratovic and Admir Hadzimuratovic (2012). Evaluation and Emergency Treatment of Criticlly III Neonate with Cyanosis and Respiratory Distress, Congenital Heart Disease - Selected Aspects, Prof. P. Syamasundar Rao (Ed.), ISBN: 978-953-307-472-6, InTech, Available from: http://www.intechopen.com/books/congenital-heart-disease-selected-aspects/evaluation-and-emergencytreatment-of-criticlly-ill-neonate-with-cyanosis-and-respiratory-distress

\section{INTECH}

open science | open minds

\section{InTech Europe}

University Campus STeP Ri

Slavka Krautzeka 83/A

51000 Rijeka, Croatia

Phone: +385 (51) 770447

Fax: +385 (51) 686166

www.intechopen.com

\section{InTech China}

Unit 405, Office Block, Hotel Equatorial Shanghai

No.65, Yan An Road (West), Shanghai, 200040, China

中国上海市延安西路 65 号上海国际贵都大饭店办公楼 405 单元

Phone: +86-21-62489820

Fax: $+86-21-62489821$ 
(C) 2012 The Author(s). Licensee IntechOpen. This is an open access article distributed under the terms of the Creative Commons Attribution 3.0 License, which permits unrestricted use, distribution, and reproduction in any medium, provided the original work is properly cited. 